\title{
AERODYNAMIC CONCEPT OF THE UAV IN THE GYRODYNE CONFIGURATION
}

\author{
Jan Muchowski*, Marek Szumski*, Andrzej Krzysiak** \\ *Department of Fluid Mechanics and Aerodynamics, Mechanical Engineering and Aeronautics, \\ Rzeszow University of Technology, al. Powstańców Warszawy 8, 35-959 Rzeszow \\ **Aerodynamics Department, Institute of Aviation, Al. Krakowska 110/114, 02-256 Warsaw \\ jmuchowski@wp.eu, marek.szumski@prz.edu.pl, andkrzys@ilot.edu.pl,
}

Abstract

The article presents an aerodynamic concept of UAV in the gyrodyne configuration, as a more efficient one than the currently used UAV airframe configuration applied for monitoring tasks of power lines and railway infrastructure. A sample task which is realised by conceptual gyrodyne based on monitoring aerial power lines was characterised and described. The assumed idea of UAV was shown in comparison to the currently used aircraft configuration presented in the introduction. Referring to momentum theory, hover efficiency of the multicopter and the helicopter was evaluated. In relation to the helicopter, an initial draft of the airframe conception accompanied by a description of advantages of the gyrodyne configuration was exposed. Problems related to the gyrodyne configuration were emphasised in the summary.

Keywords: aerodynamic concept, UAV, VTOL, gyrodyne, airframe configuration

\section{INTRODUCTION}

In recent years a dynamic growth of the UAV (Unmanned Aerial Vehicle) usage in civil and military missions can be observed . Economic aspects are the main reasons of that increase, i.e. the purchasing cost of the UAS (Unmanned Aircraft System) varies from 40\% up to $80 \%$ of the manned system cost. When considering a solution to an analogical problem, the cost of an unmanned system's usage equals $40 \%$ of the expenses of a manned system [1].

Among a wide range of missions of the UAV, an exceptional case can be highlighted. The main goal of the mission is to monitor/patrol/inspect energy and railway infrastructure, for instance, aerial power lines, gas pipes, wind farms, railway lines etc. [2]. It has been proposed to call that type of infrastructure 'a linear-puncture infrastructure'. The justification of such an appellation is to emphasize the necessity 
of cruising along specified routes between critical places (e.g. aerial power line masts) and hovering or maneuvering typical for the helicopter in those critical places. In such cases, manned helicopters have been used so far [2]. Attempts in the UAV of various helicopter configurations are being made to reduce costs of completing the task $[2,3]$.

Mission analysis performed by UAV and the economic aspect are parts of technical requirements, which influence directly the features of the new construction [4]. The key element of the design is to choose an optimal airframe configuration, which fulfils previously set technical requirements. An economic analysis concerning power efficiency might suggest an existence of a better solution of the airframe configuration meant to be used in the prescribed task. First of all, in this particular situation, it would be crucial to specify technical requirements while monitoring a linear-puncture infrastructure on the basis of an example mission. The next step should be to overview, characterise and compare the existing airframe configuration and try to select an optimal configuration.

\section{EXAMPLE TASK - FORMULATION OF INITIAL TECHNICAL REQUIREMENTS}

A proper example of a task based on monitoring of linear-puncture infrastructure might be a visual inspection of an aerial power line (Fig. 1). That mission consists of two basic phases supplemented by phases of takeoff and landing between obstacles i.e., in a limited area. The first one is a forward flight along a power line (Fig. 1, phase 4.), between a punctual object (in this particular case, a power mast). Forward flight has to be performed with a moderate speed near the line and enable a visual inspection of the line's conditions. The second one concentrates on a slow flight, hovering and helicopter maneuvering in the vicinity of power masts. (Fig. 1, phase 3.) Examples of the UAV usage for energy line inspection can be found in [2]

To formulate initial technical requirements, a flight time proportion between the first and the second phases has been assumed. An exact definition of proportions between effectiveness of hovering, low speed flight and forward flight requires a detailed analysis of this particular mission. That proportion will have a crucial meaning in the forthcoming designing process, and will become a starting point of a possible optimization of the new UAV airframe.

In order to make an estimation, one section of an aerial power line including two masts and a distance between them have been assumed. A typical inspection of a technical condition of a power mast should take one minute. An average distance between power masts in Poland varies from $300 \mathrm{~m}$ up to 1,000 metres and depends on the type of power line and landform. Assuming an average speed between power masts, which equals $10 \mathrm{~m} / \mathrm{s}$, it appears that depending on a particular power line, hover phase and helicopter maneuvers constitute from $50 \%$ to $80 \%$ of overall flight time.

\section{OVERVIEW OF AIRFRAME CONFIGURATIONS}

Based on foregoing tasks, a division of airframe configuration considering their hover possibility, take-off and landing methods has been established. Therefore, among diverse configurations a vertical take-off and landing (VTOL), and a horizontal take-off and landing (HTOL) can be distinguished. It has to be pointed out that VTOL has a possibility of hover, while HTOL does not. There is a wide variety of particular construction solutions and for that reason only the most significant airframe configurations used in the UAV have been presented in the article. 


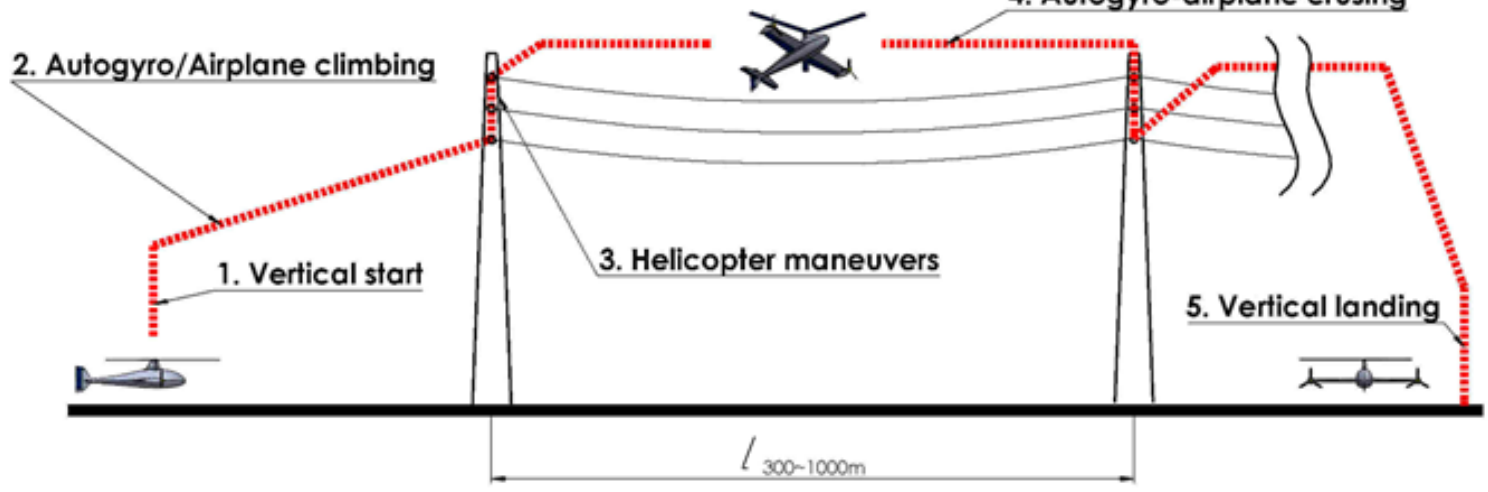

Fig. 1. The example of power line inspection mission profile done by UAV in gyrodyne configuration [Muchowski, Szumski, Krzysiak 2017]

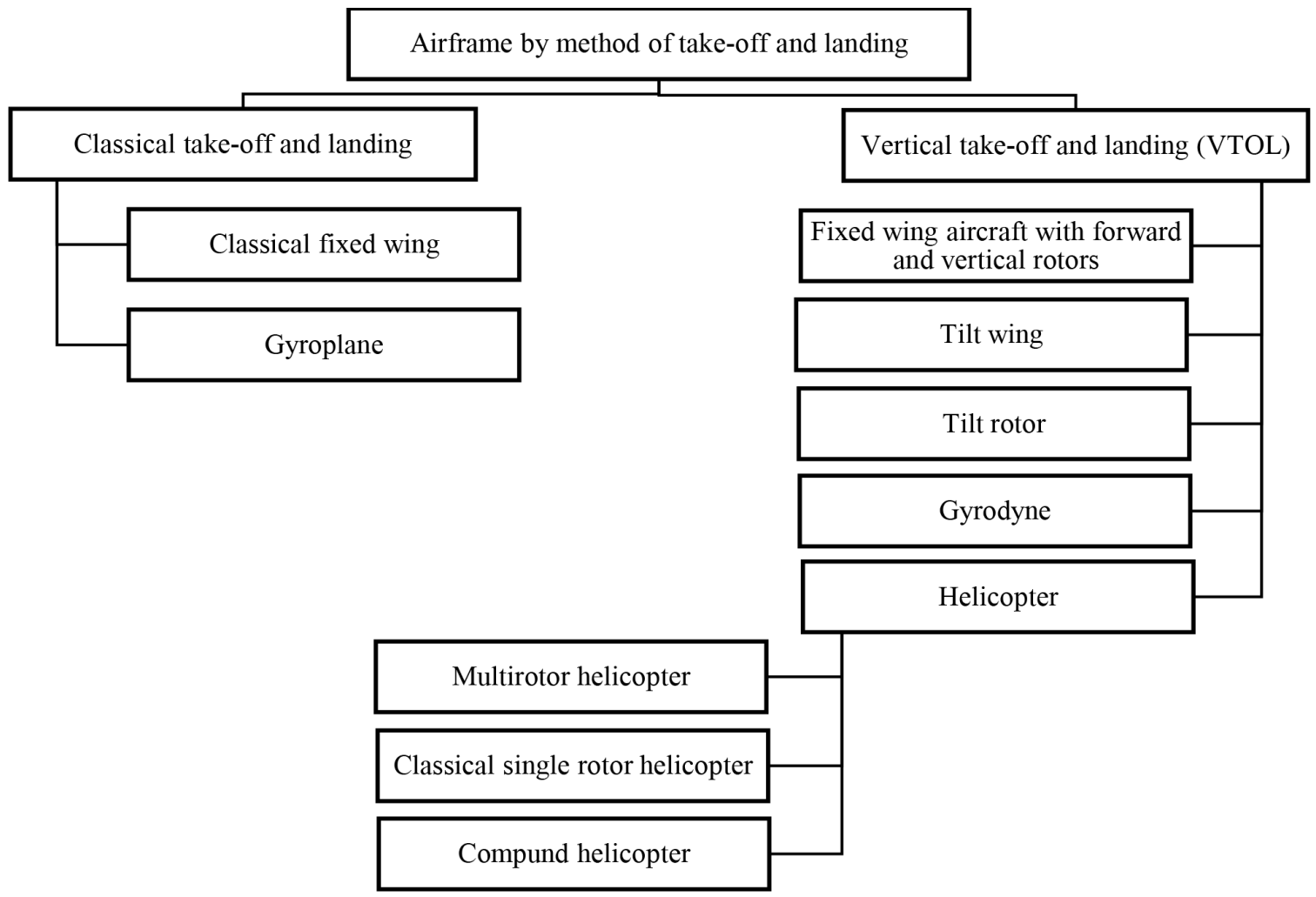

Fig. 2. Airframe classification by method of take-off and landing [Muchowski, Szumski, Krzysiak, 2017].

A fixed wing is an airframe type, in which the only method of take-off and landing is horizontal (HTOL). Lift is produced during all flight phases by the fixed wing as a result of a relative movement 
of the air. Forward thrust is provided by the propeller or the jet power unit. The fixed wing can be constructed as: a classical one , a flying wing, a canard or a tandem configuration. Historically, the first successful UAV was Lawrence and Elmer Sperry's aircraft built in a fixed wing configuration in 1916 [5] (Fig.3).

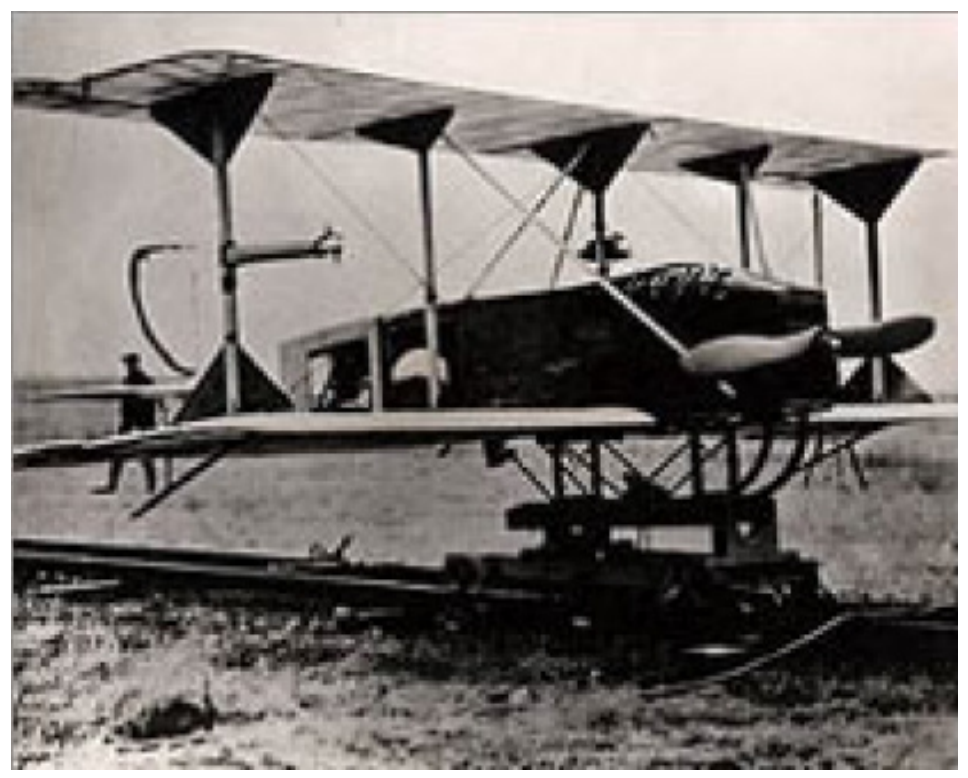

Fig. 3. Lawrence and Elmer Sperry (Photo [5], 1916).

The gyroplane is a HTOL aircraft. Lift is produced by the main rotor using autorotation phenomena. The main rotor is driven by relative wind flow thorough the rotor disc. Forward thrust is produced by the propeller. Gyroplane control is achieved by pitch and roll of the rotor disc.

In fixed wing aircraft with forward and vertical rotors configuration (Fig.4), lift in horizontal flight is produced by the wing analogically to the classic fixed wing. To accomplish a vertical take-off, landing and hovering such aircraft uses independent propulsion. Axis of propulsion force is approximately parallel to the vertical axis of aircraft and cannot change its position. Thrust necessary for forward flight is provided by propulsion, in which their axis is parallel to the longitudinal axis of aircraft. Control in vertical flight is established by changing power on each independent vertical rotor. In horizontal flight control takes place through deflection of control surfaces on the wings and the tail.

Whereas in tail sitter configuration (Fig.5), rotor or rotors generate thrust for forward flight, hover, vertical takeoff and vertical landing. Propulsions are permanently attached to the airframe structure and their axes of thrust are parallel to longitudinal axis of the aircraft. Lift to horizontal flight is produced by the wing. It means that such a configuration has to rotate around the lateral axis to make a transition from vertical flight to forward flight. Control in forward flight is similar to the fixed wing configuration, meanwhile control in hover is established by changing the direction and the amount of thrust. That change is caused by a deflection of control surfaces. 


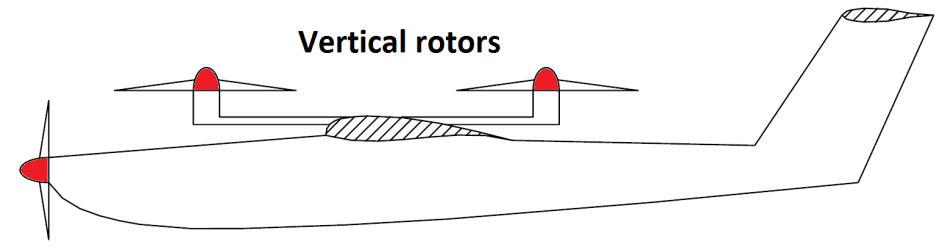

Horizontal propulsion

Fig. 4. Fixed wing aircraft with forward and vertical rotors [Muchowski, Szumski, Krzysiak, 2017].

\section{Tilt-Wing-Body}

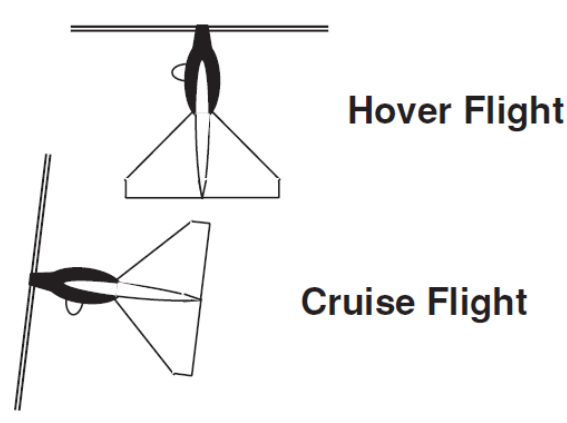

Fig. 5 Transitioning VTOL UAV-tail sitter [1].

Tilt rotor (Fig. 6) has propulsions attached to the wingtips. For rotors it is possible to rotate from vertical to horizontal position depending on a flight phase. In the case of tilt wings (Fig.7) the propulsions are permanently attached to the wing which can rotate. During hovering in tilt, the rotor and tilt wing propulsions are in a vertical position and produce thrust necessary to balance aircraft weight. On the other hand, in forward flight propulsions are in a horizontal position and generate thrust. The wing produces lift in that phase. In both tilt configurations, control in forward flight is similar to that in a classical fixed wing. In hover, control is performed by changing the direction and the amount of thrust on rotors.

\section{$\underline{\text { Tilt-Rotor }}$}

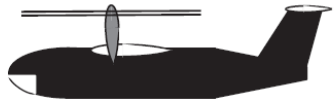

Hover Flight

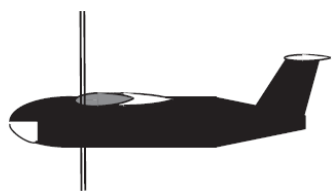

Cruise Flight

Fig. 6. Tiltrotor Bell Eagle Eye UAV [1]. 


\section{Tilt-Wing}

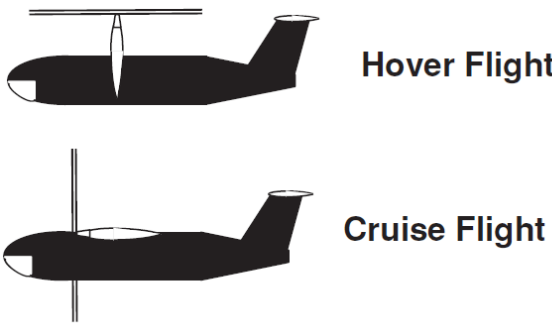

Fig. 7 Tiltwing UAV [1].

Regarding the helicopter, the main rotor is used to generate lift and thrust in all phases of flight. A classical single rotor helicopter uses the tail rotor to counteract the torque effect. Control over a classical single rotor helicopter is established by a change of cyclic and collective pitch on the main rotor and collective pitch on the tail rotor. Helicopters can be built in a single-rotor and multi-rotor configurations.

The most significant difference between multi-rotor and single-rotor helicopter is the lack of the tail rotor. Various multi-rotor types can be distinguished. The most significant and popular one among the UAVs is the multicopter (Fig 8). Majority of multicopters do not use complicated mechanical control system (swash plate). Control is provided by changing thrust on each independent rotor (constant pitch propellers).
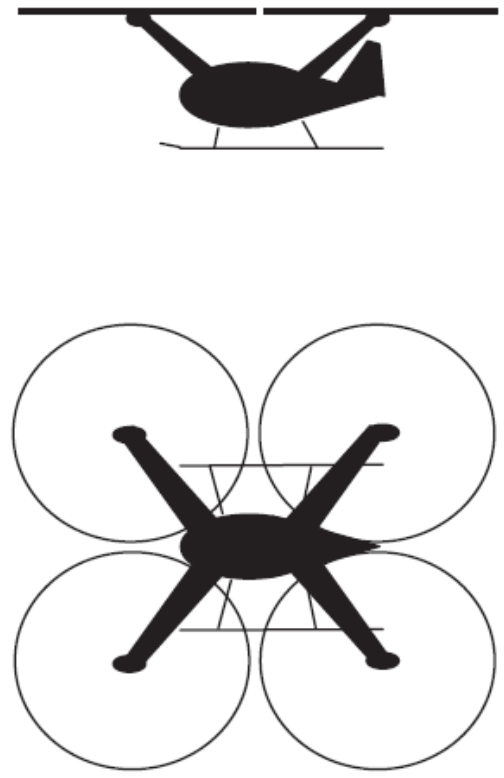

Fig. 8. AV in multicopter (quadrocopter) configuration [1]. 
An attempt to improve the helicopter's performance including particularly an increase of its maximum speed in forward flight is a configuration type called the compound helicopter. Usually, it is a configuration similar to a classical helicopter, which depending on a specific construction can have: supplementary forward flight propulsions positioned in the longitudinal axis of the helicopter, wings and stabilizers. Control of that configuration is similar to a classical helicopter. Control in forward flight can be realized by changing collective and cyclic pitch on the rotors and defecting control surfaces on the wings and the stabilizers. Additional wings and forward flight propulsion is to unload the rotor which can rotate with a lower speed and with diminished effects of high Ma number flow. $[11,12,13]$. Limited flight velocity of classical helicopter is a consequence of asymmetric flow conditions encountered by the rotor in forward flight. The blade velocity is a geometrical sum of forward speed of a helicopter and rotation speed of the blade. With the growth of forward speed, the speed on the advancing blade increases and on the retreating blade decreases. It provokes an appearance of wave, effects the advancing blade, an increase of the area of reverse flow region, and a possibility of a dynamic stall on the retreating blade. These phenomena are highly unfavorable and constitute a limitation in achieving high speeds by helicopters [12].

The gyrodyne (Fig. 9) combines in one construction features of a classical aircraft configuration, a helicopter and a gyroplane $[11,12,13]$. In contrast to a classical helicopter and the majority of compound helicopters, the rotor of a gyrodyne in a forward flight works in a state of autorotation generating a component of lift. Another component of lift is generated by the wing. In a vertical take-off, landing and hover, lift is generated by the main rotor which works as in a classical helicopter. Thrust needed for forward flight is supplied by additional forward propulsions. According to a specific construction type, torque effect (in the case when the main rotor is driven by shaft) can be counteracted by the tail rotor or supplementary forward propulsion (e.g. Fairey Gyrodyne). As an example of a successful construction in a configuration of a manned gyrodyne Fairey Rotodyne from 1957 [12,14].

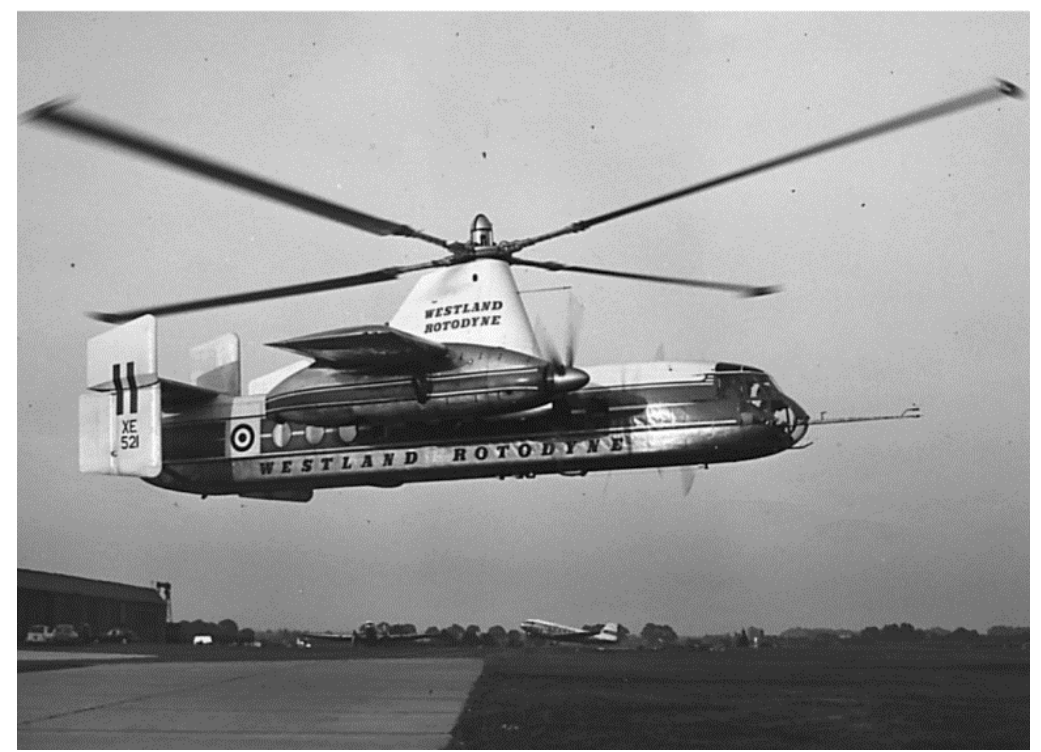

Fig. 9. Fairey Rotodyne as an example of gyrodyne [14]. 


\section{COMPARISON OF PERFORMANCE FOR VARIOUS TYPES OF AIRFRAME CONFIGURATION}

The comparison of flight performances is complicated due to insufficient specified data. It is particularly true for the UAV category and the previously described mission. The analysis exhibited below includes only power required for flight and its results are indicative (as based on literature). A short examination of the application described in the previous paragraph shows a great contribution of hovering in completing the task. A choice of an optimal solution of UAV airframe configuration should mainly focus on a configuration providing effectiveness of hovering, low and moderate speed flying contrary to the effectiveness of high speed forward flying. It implicates an elimination of the classical and gyroplane airframe configuration from further studies.

The following assumptions have been established to compare power required for flight for different prescribed aircraft configuration types:

- required power for helicopter and gyrodyne flight has been taken from [15]

- disparity in the required power for hover has been estimated using the momentum theory, undertaking same maximum take-off weight and maximal dimensions according to Fig. 11.

- required power in forward flight for the helicopter and the gyrodyne has been defined on the basis of Fig. 12 adopting a speed of $80 \mathrm{kn}$, which corresponds to proximate minimum speed of the aircraft with a similar take-off weight to the one proposed in the calculations

- tiltrotor configuration has a similar demand for power needed to forward flight as aircraft

- required power in forward flight $\left(\mathrm{V}_{\min }\right)$ for the tiltrotor has been assumed equally to the required power in the helicopter's forward flight. This presumption was made on the basis of [11]

- power requirement for various airframe configurations and different flight phases has been introduced as non-dimensional, for reference value the power required to hover for the helicopter has been taken and assigned in Chapter 1 of this paper.

\subsection{Hovering efficiency estimation}

The following graph (Fig. 10) can be useful for an initial evaluation of hovering efficiency of different types of airframe configuration. It has been prepared for manned vertical lift aircrafts and depicts the relation between hovering efficiency vs. disc loading. The graph refers to [12] and has been modified by the authors by adding a gyrodyne. Gyroplane performance data has been taken from [15].

From the graph above, it follows that the best airframes in terms of hover efficiency are: the helicopter, the gyrodyne, the compound helicopter and the tiltrotor. The aforesaid graph has been prepared respecting data about manned aircrafts which are designed with various assumptions. Consequently, power loading and effective disc loading cannot relate to micro and mini UAV categories. The discussed graph lacks the multicopter, which is significant for further examination. Therefore, basing on momentum theory, the power required for hovering a helicopter, a multicopter and a tiltrotor will be estimated.

The hovering efficiency depends mainly on disc loading and it is described in the momentum theory. Neglecting other effects it has been estimated for: the multicopter Agras MG-1 DJI [16], hypothetical helicopter and hypothetical tilt rotor with similar dimensions (Fig. 11). Take-off weight of $12.5 \mathrm{~kg}$ has been assumed. The awareness of momentum theory gives underestimated power requirements for hovering. The reasons for underestimating results are: not considering energy loss on the swirl, blade tips loses, profile power, Reynolds number [17], propulsion of the tail rotor, the lack of interference between the rotor and the rest of the airframe. 
Hovering efficiency vs. disc loading for a range of vertical lift

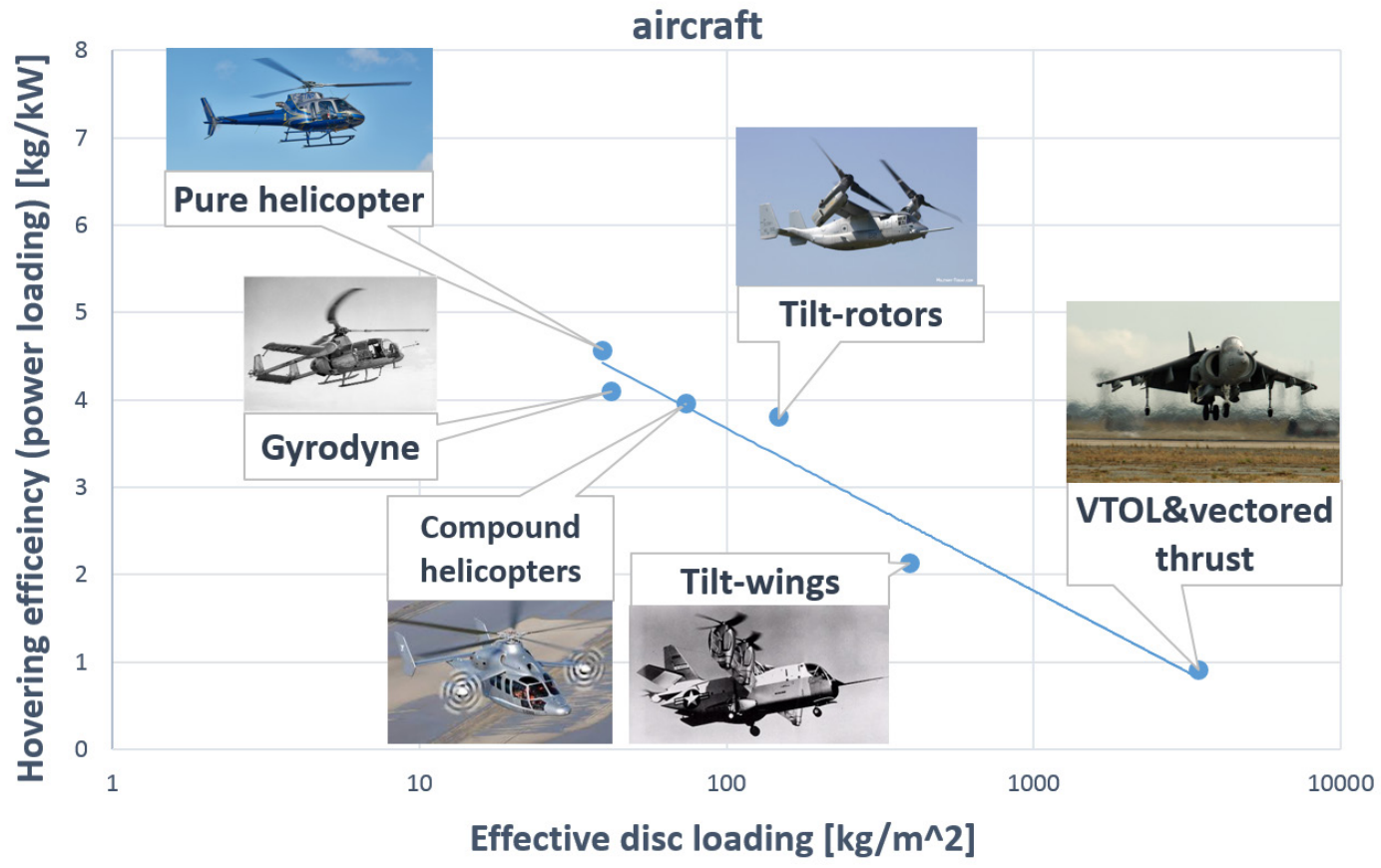

Fig. 10 Hovering efficiency vs. disc loading for a range of vertical lift aircraft-graph from [12].

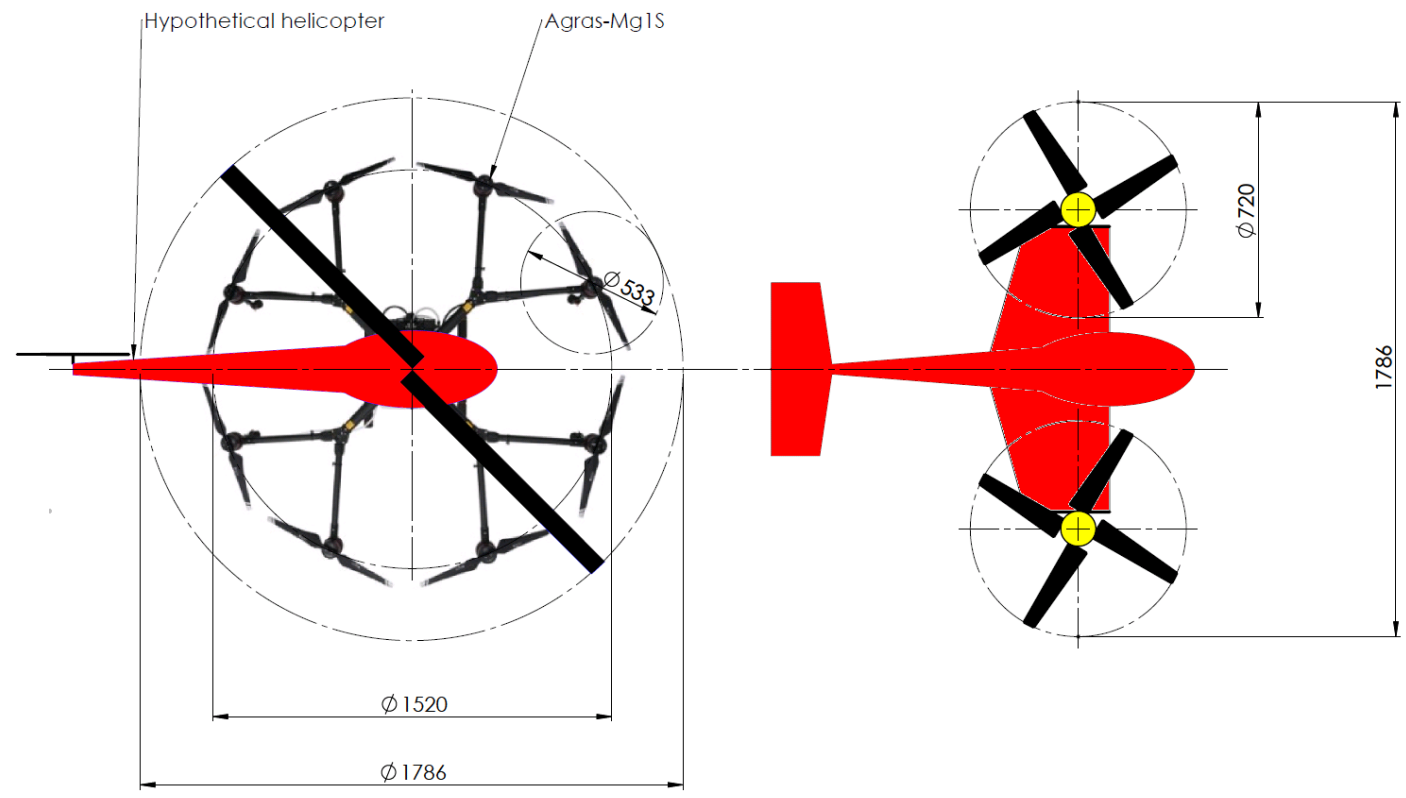

Fig. 11 Characteristic dimensions of a multicopter Argas-Mg1S, hypothetical helicopter and hypothetical tiltrotor used in calculations of required hovering power [Muchowski, Szumski, Krzysiak, 2017] 
Used formulas:

$$
\begin{gathered}
\mathrm{P}=\mathrm{T} \cdot \mathrm{v}_{\mathrm{h}} \\
\mathrm{T}=\mathrm{m} \cdot \mathrm{g} \\
v_{h}=\sqrt{\frac{T}{2 \rho A}} \\
D L=\frac{T}{A} \\
P=T \cdot \sqrt{\frac{D L}{2 \rho}}
\end{gathered}
$$

where: $\mathrm{T}$ - thrust, $\mathrm{m}$ - mass, $\mathrm{g}$ - gravitational acceleration, $\mathrm{P}$ - power in hover, $\mathrm{v}_{\mathrm{h}}$ - hover induced velocity, DL - disc loading, A - disc area, $\rho$ - air density

Calculation results show that induced power required for hovering in the case of a hypothetical helicopter equals 544 [W], for an octocopter is equal 653 [W], and for tiltrotor - 988 [W], which means that geometrically similar multicopter consumes for hovering $20 \%$ more power than a helicopter. Tiltrotor consumes $81 \%$ more power than a similar helicopter. From [15] arises that for a gyrodyne hovering induced power is $10 \%$ larger than for a similar (disc loading) helicopter.

\subsection{Horizonatal flight performance estimation}
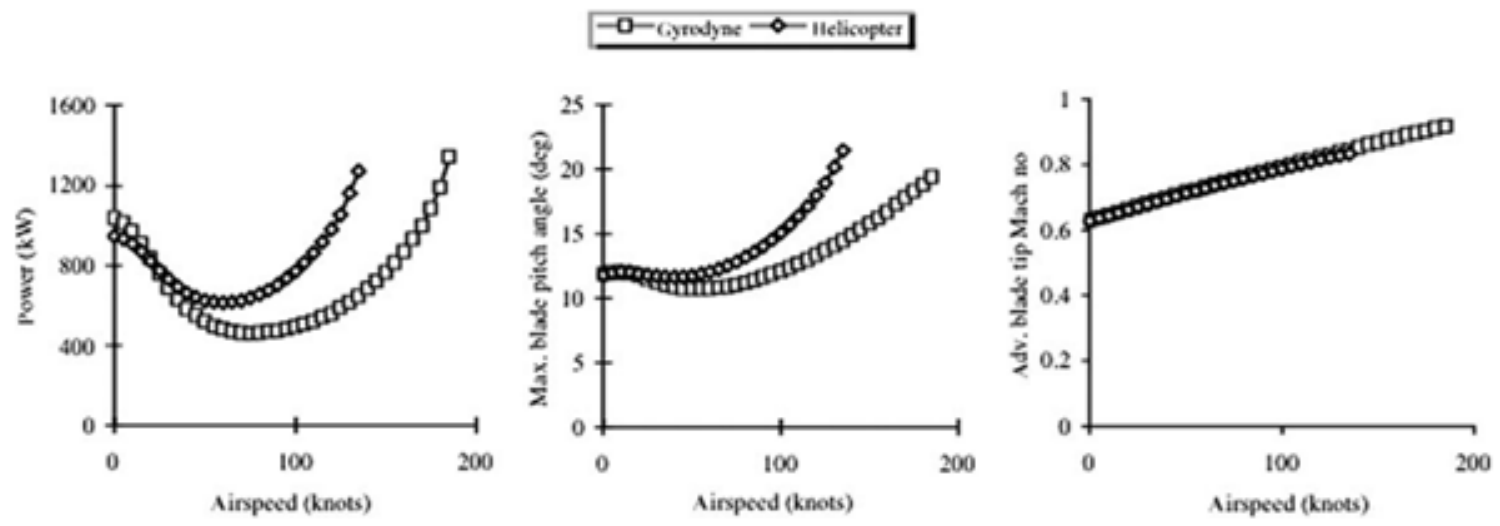

Fig. 12.Required power for flight for helicopter and gyrodyne [15].

Non-dimensional data read from the charts have been summarized in Table [Tab.1] 
Table 1. Non-dimensional power requirement for various airframe configurations and different flight phases.

\begin{tabular}{|c|c|c|c|}
\hline & Helicopter & Gyrodyne & Tilt rotor \\
\hline Hover & 1 & 1.1 & 1.81 \\
\hline Horizontal flight & 0.6 & 0.4 & 0.6 \\
\hline Mission 1-hover time/forward flight time equals 0.5 & 0.8 & 0.75 & 2.11 \\
\hline Mission 2-hover time/forward flight time equals 0.8 & 0.92 & 0.96 & 1.56 \\
\hline
\end{tabular}

Calculated relationship between required power and hover to forward flight ratio (Fig 13) indicates that in the range from 0.1 up to 0.7 of that ratio the gyrodyne has the lowest power requirement among all the airframe configurations previously examined. It has to be considered that the conducted analysis is based on calculation results taken from [15] including some simplifications. That analysis is approximate and its role is to present an introductory assessment and justification of the gyrodyne use in the prescribed mission. Clarification of this study will be possible at the initial project phase.

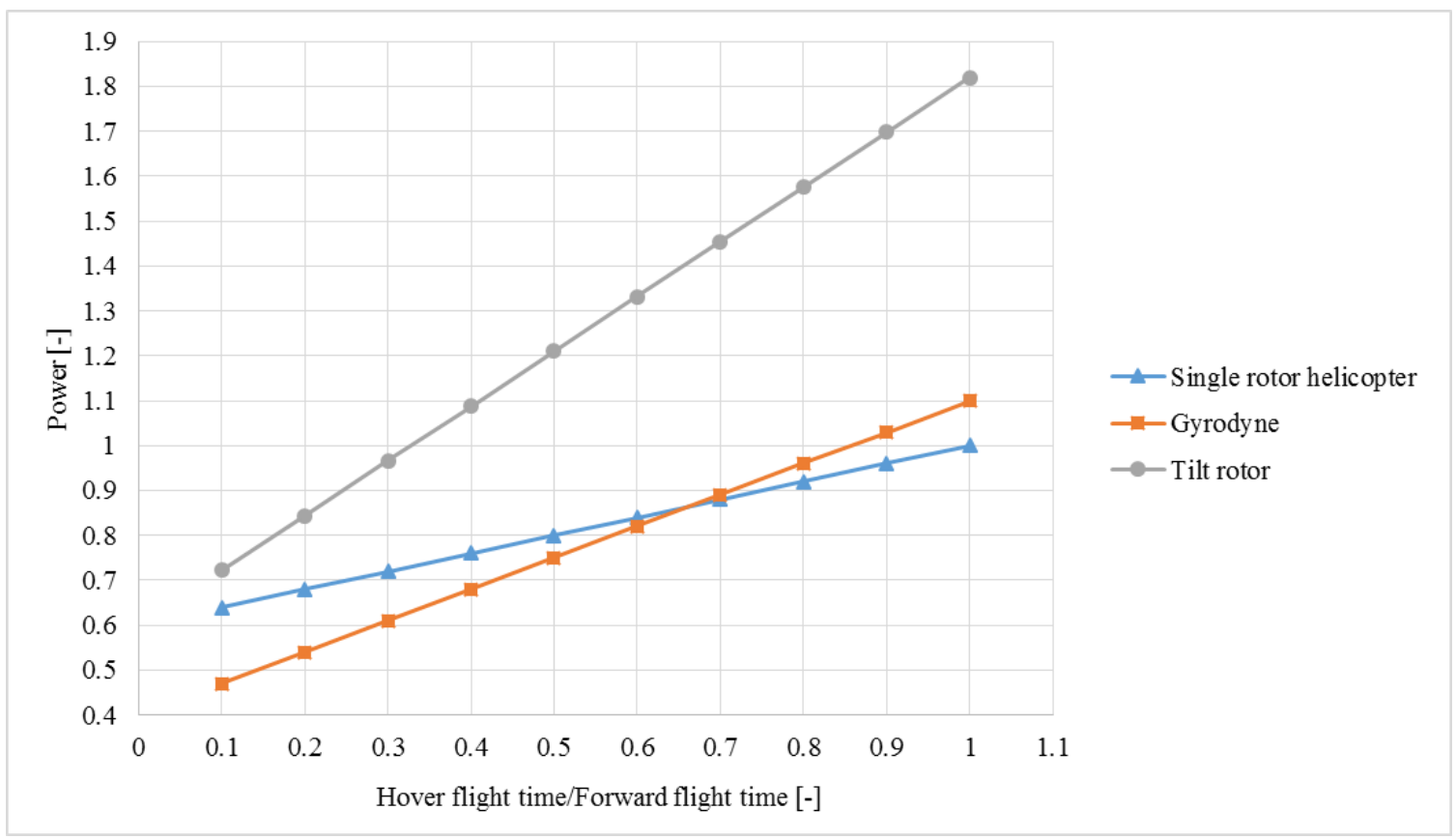

Fig. 13. Required power vs proportion between hover and horizontal flight time

\subsection{General remarks to airframe configuration}

Fixed wing constructions are more efficient in forward flight than VTOL, have a greater cruise speed and altitude of flight. However, the lack of possibilities of vertical take-off and landing creates a limitation in their usage, especially in Mini and Micro category of the UAV in the situation when take-off and landing area is limited.

Fixed wing aircraft with forward and vertical rotor. On account of the in case of wing in fixed wing aircraft with forward and vertical rotor it has a higher forward speed, altitude and above all the 
efficiency of forward flight if set together with the multicopter and the helicopter. This configuration in comparison to the helicopter and the muticopter has worse hovering efficiency caused by bigger disc loading. In turn, bigger disc loading has an impact on weight of additional elements like the wings, fuselage, the stabilizers and forward flight propulsion.

Tail sitter - a flight transition is complicated in respect of control and requires large space [6]. Another problem might be a proper placement of sensors or cameras, for which it has to be possible to constantly gaze in the direction of the ground. A disc loading and effectiveness of hover is similar to the fixed wing aircraft with forward and vertical rotors.

Tiltrotor and tiltwing. Those two types of aircraft have worse efficiency of hovering if compared to the helicopter, but they reach greater forward flight speed and are more economical in forward flight. The features of that kind of aircraft is a sophisticated construction and complicated transition maneuvers $[7,8]$. The forthcoming drawbacks pose a high risk of usage in situations when one of the propulsions gets damaged [9] and in the majority of configurations of that type it is impossible to land while rotor axes are in a horizontal position.

Helicopter- thanks to the lowest disc loading, it reaches the highest hovering efficiency among all the other types of VTOL. The helicopter compared to the multicopter achieves higher speed and efficiency of forward flight. Relating to the multicopter, its disadvantages lie in a more complicated construction and more difficulties in operating it and less stability in hover.

Multicopter configuration features simple construction and easy control. Unfortunately, such simplicity of that configuration has drawbacks such as big consumption of power in hover and forward flight, low maximum speed of forward flight. What is more, one of the most serious risk is propulsion failure which can lead to uncontrolled fall to the ground.

To solve this problem in some mulicopter constructions parachute rescue systems are used. Parachute rescue system requires an adequate altitude for its proper work. If one uses that kind of systems it increases the weight and reduces the multicopter's performanceA simple construction and control system, hovering stability and affordability make them commonly used.

The previously prepared analysis of a monitoring mission and characteristics of the currently used UAV configuration might suggest that designing an UAV in a gyrodyne configuration is intentional. It is justified by the following arguments: a classical aircraft configuration cannot hover as well as make helicopter manoeuvres, fly at a low speed enabling a precise examination of power line technical conditions or fly in inaccessible areas. What has been already shown, the multicopter is less effective in hover. The tiltrotor and tilt-sitter are less effective in hover. Their high forward flight performances (in contrast to the muticopter and the helicopter) cannot be used in the described mission in view of short gaps between masts. Simultaneously, a transition between hover and forward flight requires extra power. It can be supposed that the tilt wing, the tilt rotor and the tail sitter are less stable and more sensitive to wind while hovering against a helicopter and in a particular mulitcopter.

It can be expected that a properly designed gyrodyne in such a specific mission as the analysed one can be more effective than a classical helicopter, which has been demonstrated in the previous study. In the gyrodyne designed for this type of mission, an additional wing will not serve to increase the maximum forward flight speed, but to improve the economics of forward flight especially in the case of low speed requirements. 


\section{PROPOSAL OF THE PRELIMINARY CONCEPT OF UAV IN GYRODYNE CONFIGURATION}

The initial concept of UAV in the gyrodyne configuration is shown in Fig. 14. It assumes the use of low wing configuration with the purpose of gaining the furthest possible distance between the wing and the rotor due to minimization the interference of those two elements. A solution worth considering during further analysis would be mechanization of the wing providing its 90-degree rotation around the lateral axis. Some clues regarding the position and geometrical characteristics of the wing have an effect on hover download and forward flight characteristics can be found in [18]. For majority of compound helicopters, in which the rotor is driven by the engine (autorotation is used only in emergency situation), it is assumed that the wing allows to generate lift equal 30\% of aircraft weight [20]. Simultaneously, a complex wing mechanization of approximately $40 \%$ of the wings area is planned. Flaps and ailerons will be able to deflect around 90 degrees what will effectively decrease loss of lift in hover conditions

Forward flight propulsion located on tip wings except providing thrust for forward flight will have neutralized torque effect when rotor is driven by the engine. Their location on the tip wings will presumably decrease induced drag. Another factor taken into consideration is the usage of ducted propeller as a method to limit influence between the rotor and propellers.
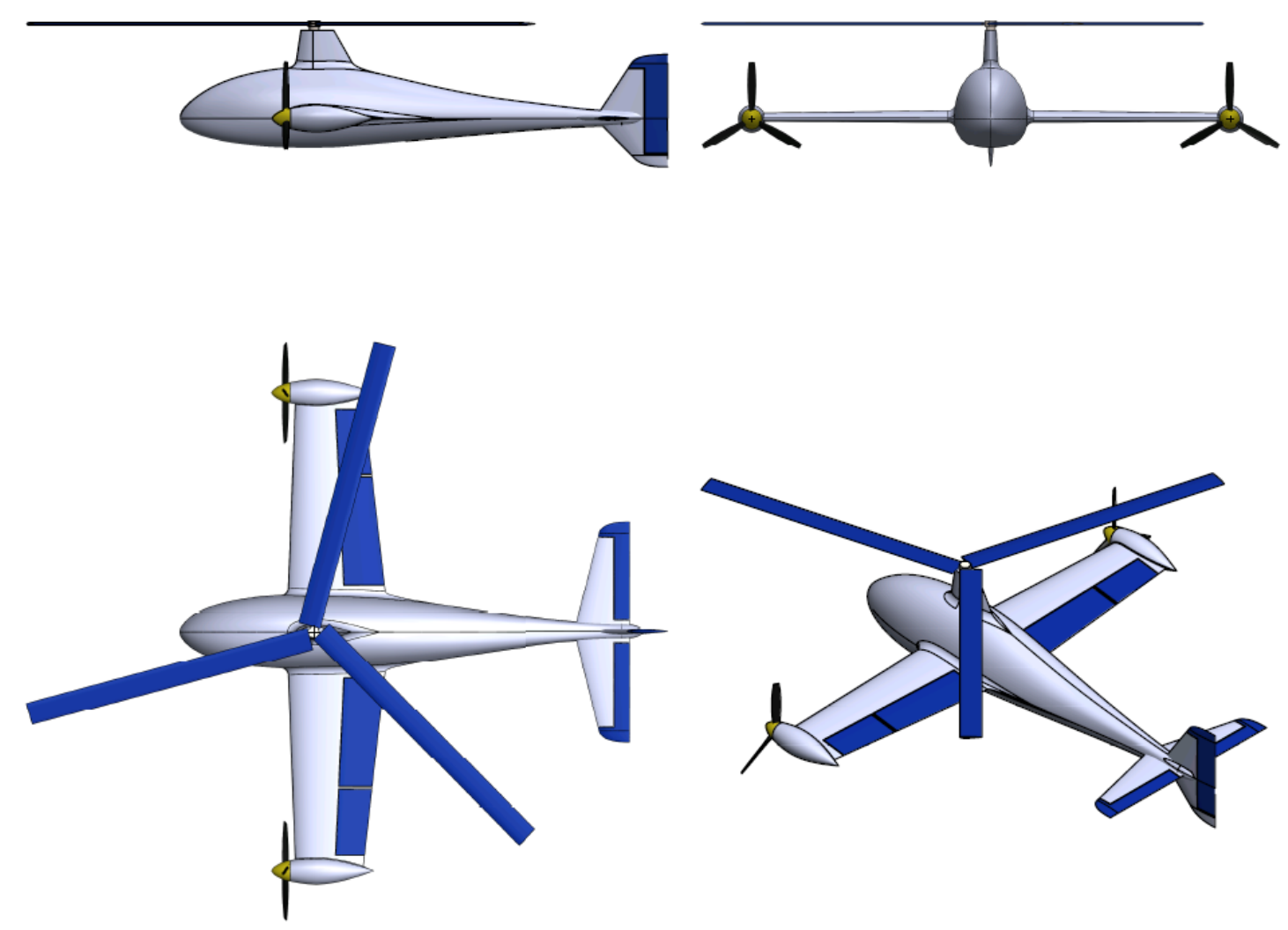

Fig. 14 Sketch of an initial conception of UAV gyrodyne. 
Taking into account the safety of use, it has been predicted for a conceptual UAV to be safer than the previously described airframe configurations. Due to the fact that autorotation is a normal state of flight, in case of a failure of any propulsion element, the UAV will be able to land in the limited area using the phenomenon of autorotation. The forthcoming positive feature of the flight in the autorotation mode is the lack of downwash of the air beneath the rotor, which is said to be useful in some particular cases such as the mission of analysis of air pollution.

It has been predicted, that the UAV in the depicted conception right after take-off, hover or helicopter maneuvers transits to the autorotation flight as soon as possible to let the wings start generating lift. In a compound helicopter, without a possibility of autorotation - in the case of a normal forward phase of flight - the wing is flown with a great angle of attack (Fig. 15), which impairs performance of hover and low-speed flight as compared to a classical helicopter. In those circumstances, the wing strongly effects the rotor, slowing down the flow below it $[18,19]$.

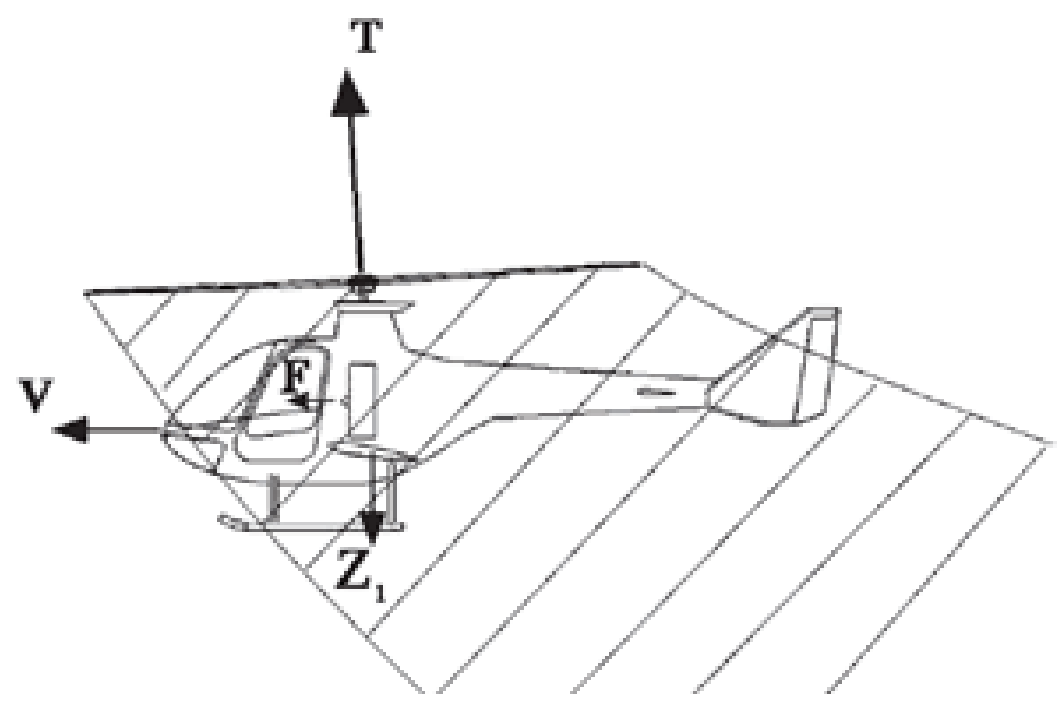

Fig. 15 Slow forward flight of compound helicopter. T-rotor thrust, $Z_{1}$-aerodynamic load, V-forward speed, F-propeller thrust [19].

In of autorotation state of flight, where the flow through the rotor is in the opposite direction [21] than in the helicopter, (Fig. 16, 17) the wing may work on a positive angle of attack even during low speed flight. Growth of forward speed enables an increase of lift generated by the wing required for horizontal flight. Decrease of disc loading causes a reduction of power consumed by the rotor. Apparently, in an autorotation the rotor is unpowered by the engine, but it consumes energy from the air flow. The question is, how the wing will be interacting with the rotor in autorotation. Unfortunately, literature sources describing experimental data or calculations regarding that problem are unknown for the authors. Using autorotation for forward flight in a compound helicopter without wings is irrational due to the fact that the gyroplane requires more power to analogical flight than a similar helicopter does (not taking into account a small range of speed). Assessment of performance depicts Fig. 18 and describes [11,12]. 
(a) Autogiro

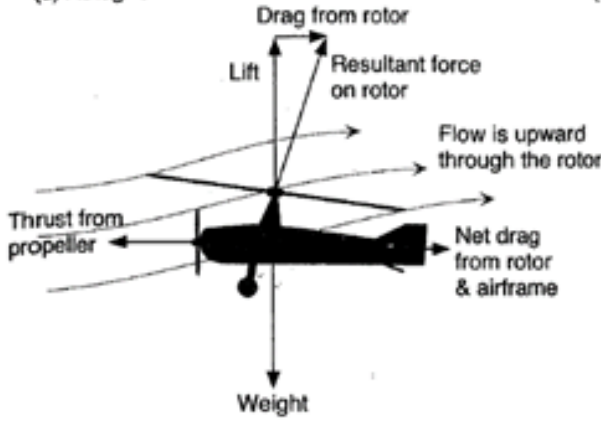

(b) Helicopter

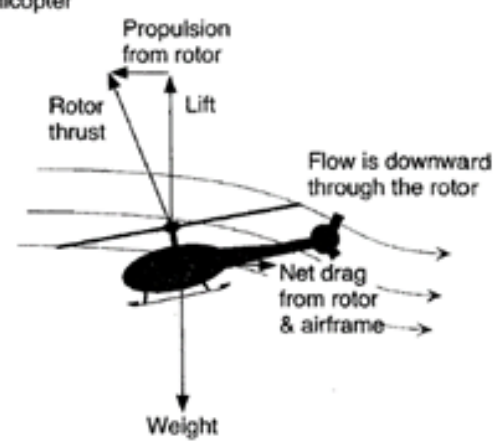

Fig. 16. Comparison of forces and flow conditions for autogyro and helicopter [12].
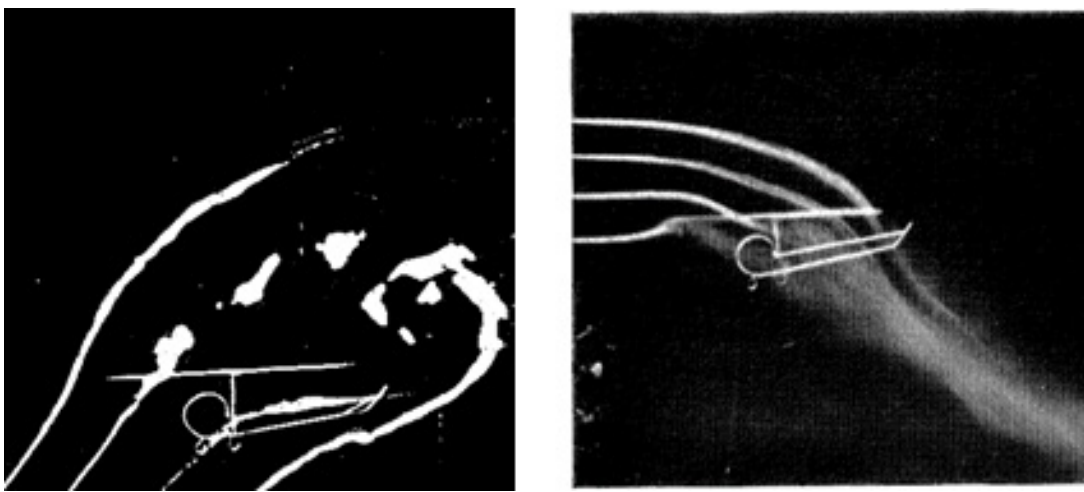

Fig. 17 Flow visualisation on autorotation (left) and helicopter rotor (right) [21]

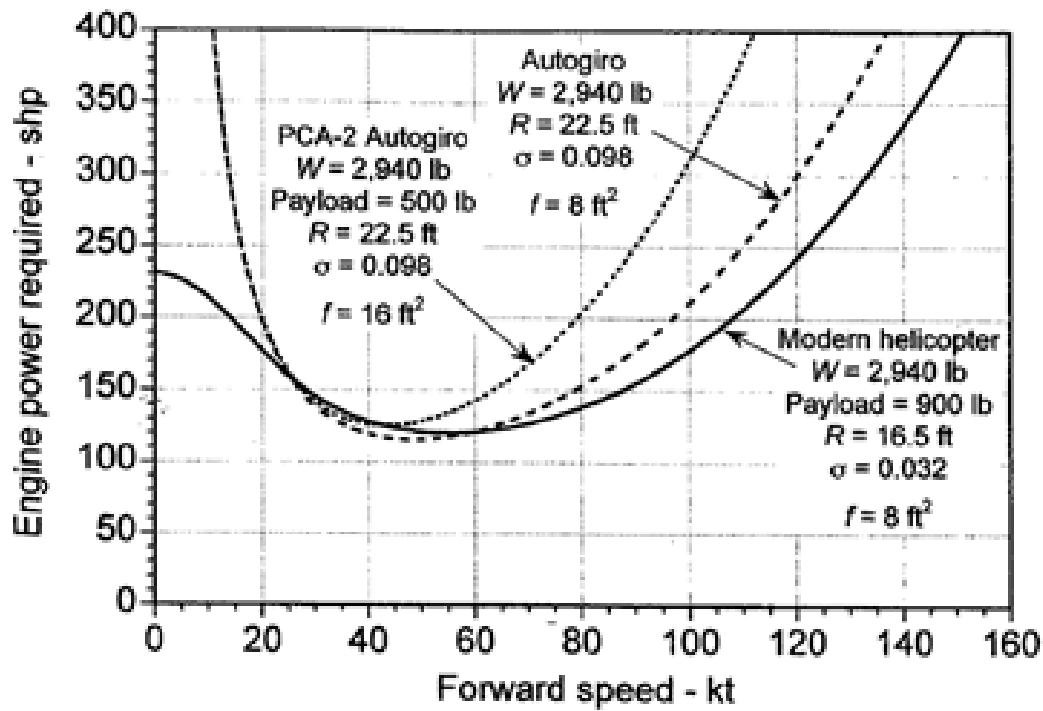

Fig. 18. Comparison of the power required for flight of a autogyro versus that of a helicopter [12] 


\section{CONCLUDING REMARKS}

In the article has been presented the initial concept of UAV in gyrodyne configuration focusing on the preliminary aerodynamic analysis. The aim of designing the new UAV configuration was a reduction of costs of the monitoring linear-point missions, for instance, an aerial power line monitoring. In the phase of the preliminary concept of the gyrodyne, a sample task has been analysed, which became a starting point for a formulation of overall technical requirements regarding phases of flight. In the following mission proportions between hover and forward flight to overall flight time which varies from 50 up to $80 \%$ have been described.

Afterwards, on the basis of short characteristics of the currently used UAV configurations the efficiency of hover and vital utility features have been analysed. It enabled a limited selection of an optimal airframe configuration for the presented mission for the helicopter and the compound helicopter.

In relation to the analysed materials, it can be stated that is possible to design the UAV in the gyrodyne configuration which is predestined to be more effective than a classical helicopter. Except for the forecasted improvement of the economics of flight another advantage it brings is higher flight safety For the gyrodyne UAV an autorotation is a normal state of flight, while in the case of helicopter autorotation is applied only in emergency situations.

A sketch of a preliminary concept with a general description of predicted solutions has been shown as an example.

It should be emphasised that the presented analysis has an introductory character and the described concept is a beginning of a further analysis about validity of the usage of gyrodyne configuration in the prescribed mission. Furthermore, it is necessary to specify technical requirements, which means - with regard to future missions - collecting more precise information, for instance, from operators of energy infrastructure. The forthcoming step towards accomplishing a conceptual design will be a preparation of aerodynamic models of a helicopter and a gyrodyne configurations in order to examine them better. It is a result of the lack or difficult access to data concerning comparison of the gyrodyne and the helicopter, especially aerodynamic characteristics of the gyrodyne in autorotation as well as the effect of position between the wing and the rotor in that state. It can also be considered to build simple models in order to test them either in a wind tunnel or RC models in flight. Assumptions established in the article were focused on the aspect of flight efficiency of a gyrodyne in contrast with different configuration types. In the initial concept, construction and control problems were not taken into consideration. The above mentioned problems are predestinated as more complex than in the helicopter. As an essential question to be answered in further work is the one concerning control in transition state of flight.

\section{BIBLIOGRAPHY}

[1] Reg, A., 2010, Unnamed aircraft system of UAVS design, development and deployment, A John Wiley and Sons, Ltd.

[2] Dudek, B., 2011, „Live working in industrial network” ("Prace pod napięciem w sieci przesyłowej”), Handbook INPE No. 36, (in Polish).

[3] Dudek B. and Czapaj R., 2007, „Advances in robotics and IS techniques in network works, especially under voltage” („Postęp w dziedzinie robotyzacji i technik SI w pracach sieciowych zwłaszcza pod napięciem”), IX Conference „Live working in nn, SN and WN networks in Poland and in the world), pp. 19-30 (in Polish). 
[4] Galiński, C., 2016, Selected Problems of Aircraft Design (Wybrane Zagadnienia Projektowania Samolotów), Institute of Aviation, Warsaw (in Polish).

[5] Nonami, K., 2007, Prospect and recent research \& development for civil use autonomous unmanned aircraft as UAV and MAV, Journal of System Design and Dynamics, Vol.1, No.2, pp.120-128.

[6] Osborne, S., R., 2007 Transitions between hover and level flight for a tailsitter uav, Thesis submitted to the faculty of Brigham Young University in partial fulfillment of the requirements for the degree of Master of Science Department of Electrical and Computer Engineering Brigham Young University.

[7] Okada, N., Kubo, D., Muraoka, K. and Sato, M., 2012, Transition flight of quad tilt wing vtol uav, Japan Aerospace Exploration Agency, 28th Congress of the International Council of the Aeronautical Sciences.

[8] Yuksek B., Vuruskan, A., Ozdemir, U., Yukselen, M., A., and Inalhan, G., 2016, Transition Flight Modeling of a Fixed-Wing VTOL UAV, Springer Science+Business Media Dordrecht.

[9] Szabelski, K., Ed., 1995, Introduction to helicopter construction (Wstęp do konstrukcji śmigtowców) Transport and Communication Publishers, Warsaw (in Polish).

[10] Juriew, B., J., 1959, Aerodynamics of propellers and helicopters (Aerodynamika śmigiet i śmigłowców), Publishing House of Ministry of National Defense, Warsaw (in Polish).

[11] Harris F. D., 2003, Overview of Autogyros and The McDonnell XV-1 Convertiplane, NASA.

[12] Gordon Leishman J. 2005 Principles of Helicopter Aerodynamics, Cambridge University Press.

[13] Ferguson K., Thomson D., 2015, Performance comparison between a conventional helicopter and compound helicopter configurations, Downloaded from pig.sagepub.com At Cambridge Univ Library.

[14] Gibbings, D., 2004, The Fairey Rotodyne - technology before its time?, The Aeronautical Journal, Paper No. 2923.

[15] Houston, S.S., 2007, The Gyrodyne - A Forgotten High Performer? Journal of the American Helicopter Society, Vol. 52, No.4, pp.382-391.

[16] DJI Official, 2017, MG-1S. [online] Available at: https://www.dji.com/mg-1s [Accessed 16 Nov. 2017].

[17] Strzelczyk P., 2007, Selected problems of propeller aerodynamics (Wybrane zagadnienia aerodynamiki śmigię), Rzeszów University of Technology Publishing House, Rzeszów (in Polish).

[18] Stepniewski W.Z., Keys, C.N., 1978, Rotary-wings aerodynamics. Dover Publications New York.

[19] Roman K., 2008, „Experimental helicopters - flying laboratories based on the IS-2 helicopter” („Śmigłowce eksperymentalne - latające laboratoria na bazie śmigłowca IS-2”), Transactions of the Institute of Aviation, No. 194-195.

[20] Krzyżanowski A., 2010, Helicopter flight mechanics (Mechanika lotu śmigłowców), Military University of Technology, Warszawa.

[21] Drees, J. Meijer, Hendal, W. P., Airflow Patterns in the Neighborhood of Helicopter Rotors. Aircraft Eng., vol. XXIII, no. 266, Apr. 1951, pp. 107-111. 


\section{ZARYS KONCEPCJI AERODYNAMICZNEJ UAV W UKŁADZIE KONSTRUKCYJNYM GYRODYNY}

\section{Streszczenie}

Artykuł przedstawia zarys koncepcji aerodynamicznej UAV w układzie gyrodyny, jako układu konstrukcyjnego sprawniejszego energetycznie spośród obecnie stosowanych układów UAV w zastosowaniu do zadań monitorowania infrastruktury energetycznej i kolejowej. Scharakteryzowano i opisano przykładowe zadanie realizowane przez koncepcyjną gyrodynę polegające na monitoringu napowietrznej linii energetycznej. Prezentowaną koncepcję UAV przedstawiono w zestawieniu z opisanymi we wstępie aktualnie stosowanymi układami UAV oraz oceniono na podstawie teorii strumieniowej sprawność zawisu dla przykładowego UAV w układzie multikoptera i śmigłowca. Następnie pokazano szkic koncepcji wraz z opisem spodziewanych zalet układu gyrodyny w stosunku do układu śmigłowca z jednoczesnym podkreśleniem w podsumowaniu możliwych problemów wynikających z przyjętego układu.

Słowa kluczowe: koncepcja aerodynamiczna, UAV, VTOL, gyrodyna, układ konstrukcyjny. 